\title{
Can Neuron Specific Enolase Be a Diagnostic Biomarker for Neuronal Injury in COVID-19?
}

\author{
Latha Ganti $^{1}$, Enrique Serrano ${ }^{2}$, Hale Z. Toklu ${ }^{3,4}$ \\ 1. Emergency Medicine, University of Central Florida College of Medicine, Orlando, USA 2. Neurology, University of \\ Central Florida College of Medicine, Orlando, USA 3. Clinical Sciences, University of Central Florida College of \\ Medicine, Orlando, USA 4. Graduate Medical Education, Hospital Corporation of America North Florida Division, \\ Gainesville, USA
}

Corresponding author: Hale Z. Toklu, haletoklu@yahoo.com

\begin{abstract}
Neuron specific enolase (NSE) is a biomarker for neuronal injury. However, increased levels in cerebrospinal fluid (CSF) and serum is associated with the clinical outcome in patients with head injury, ischemic stroke, intracerebral hemorrhage, cardiac arrest, anoxic encephalopathy, encephalitis, brain metastasis, and status epilepticus.
\end{abstract}

Recently, the severe acute respiratory syndrome coronavirus 2 (SARS-CoV-2) infection, which started in China, rapidly evolved into the coronavirus disease 2019 (COVID-19) pandemic. Patients with COVID-19 have a wide range of symptoms varying from mild upper respiratory symptoms to severe illness requiring mechanical ventilation. While coronaviruses primarily target the human respiratory system, neurological symptoms are also observed in some patients. These include symptoms such as loss of taste and olfaction and diseases like cerebrovascular disorders including ischemic stroke and hemorrhages, encephalopathies, Guillain-Barré syndrome and acute disseminated encephalomyelitis.

Here we report an observation from a patient whose NSE levels increased approximately four-fold in CSF. This finding was accompanied by increased white blood cell count and elevated protein in CSF indicating neuroinflammation. Thus, we suggest that NSE may be used as a CSF biomarker in COVID-19 patients with encephalopathy.

Received 09/22/2020

Review began 09/25/2020 Review ended 10/05/2020 Published 10/19/2020

\section{() Copyright 2020}

Ganti et al. This is an open access article distributed under the terms of the Creative Commons Attribution License CC-BY 4.0., which permits unrestricted use, distribution, and reproduction in any medium, provided the original author and source are credited.
Categories: Neurology, Infectious Disease, Epidemiology/Public Health

Keywords: neuron specific enolase, nse, cerebrospinal fluid, csf, covid-19, sars-cov2

\section{Introduction}

Neuron-specific enolase (NSE) is a glycolytic enzyme, which is expressed abundantly in the neurons and neuroendocrine cells. It was first used as a tumor marker for small-cell lung cancer, neuroblastoma and other malignancies of neuroendocrine origin, and later it was introduced as a marker for brain damage [1], because it is found that the NSE levels increase in serum and cerebrospinal fluid (CSF) following acute neurotrauma as an indicator for neuronal injury and synaptic dysfunction [2]. NSE is located in the cytoplasm of the neurons. The disruption of the blood-brain barrier integrity and damage to the neuronal tissue causes the release of NSE into the CSF and then the blood [3]. Therefore the level of NSE correlates with damage [4]. NSE levels was shown to be associated with the clinical outcome in patients with serious clinical manifestations such as head injury, ischemic stroke, intracerebral hemorrhage, cardiac arrest, anoxic encephalopathy, encephalitis, brain metastasis, and status epilepticus [5].

Recently, the severe acute respiratory syndrome coronavirus 2 (SARS-CoV-2) infection, which started in China, rapidly evolved into the coronavirus disease 2019 (COVID-19) pandemic. Patients with COVID-19 have a wide range of symptoms varying from mild upper respiratory symptoms to severe illness requiring mechanical ventilation. Neurological symptoms are also observed in some patients. Previous evidence suggested that studies on the samples from patients with severe acute respiratory syndrome (SARS) have demonstrated the presence of SARS coronavirus (SARS-CoV) particles in the brain, where they were located almost exclusively in the neurons. Thus, the respiratory failure could be partially due to the neuroinvasion of the brainstem by the virus $[6,7]$.

\section{Case Presentation}

A 77-year-old white male patient admitted to the hospital with headache, nausea, respiratory distress, and pneumonia. Patient was diagnosed with COVID-19, which was confirmed with the polymerase chain reaction (PCR) from the nasopharyngeal swab. The patient had a history of atherosclerotic heart disease of native coronary artery without angina pectoris, fatty liver, and gout.

The patient had acute respiratory distress and required ventilator support on day two which continued for 


\section{Cureus}

the next 17 days. He died afterward on day 20 of the hospitalization. The patient developed hypernatremia on day eight, which was treatment-resistant and continued until day 19 . His sodium levels were $>151 \mathrm{mEq} / \mathrm{L}$ from day 11 to the end. The patient also developed acute renal failure and hepatic failure due to sepsis. (Day 16-17: alanine aminotransferase (ALT): 207; aspartate aminotransferase (AST): 186; Creatinine: 1.58 ; white blood cells (WBCs): 12,500). The patient was evaluated for meningoencephalitis and electroencephalogram (EEG) monitoring was performed for seizures.

The patient demographics, admission vitals, laboratory findings in serum and cerebrospinal fluid (CSF) analysis, and clinical outcome are summarized in Table 1.

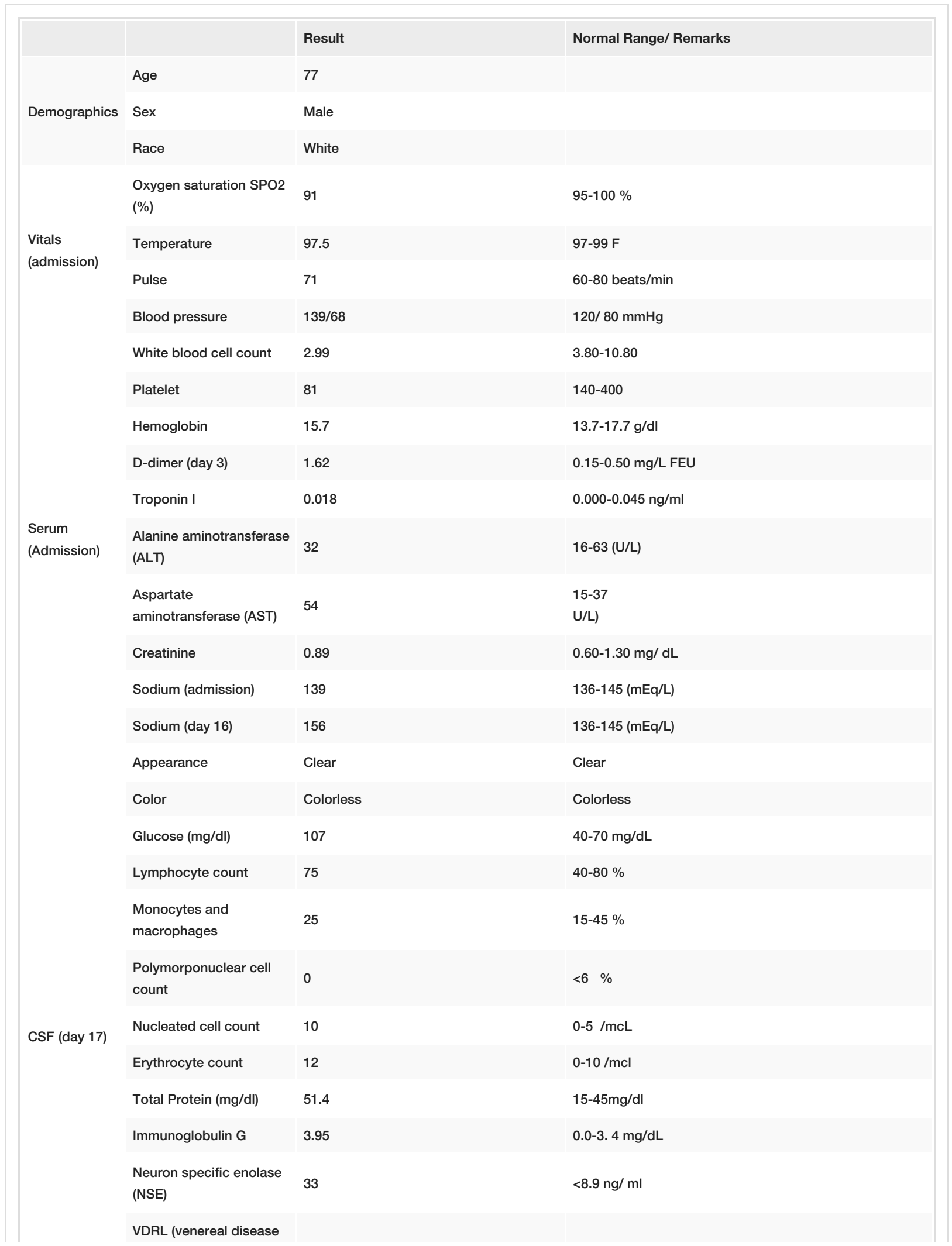




\section{Cureus}

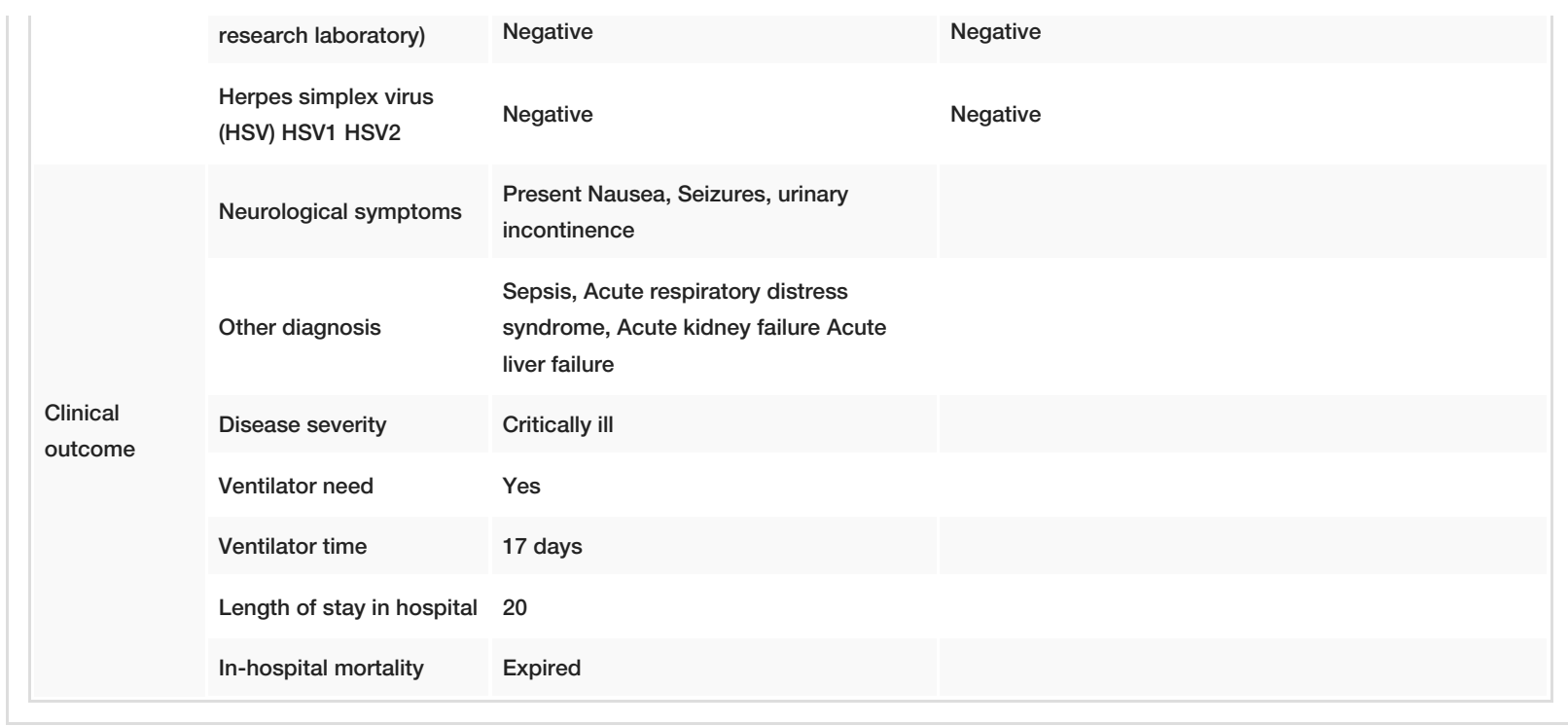

TABLE 1: The demographic characteristic, vitals, laboratory findings in serum and cerebrospinal fluid (CSF) analysis and clinical outcome

The patient's chest X-ray which indicates pneumonia and ground-glass opacities in the lung is shown in Figure 1.

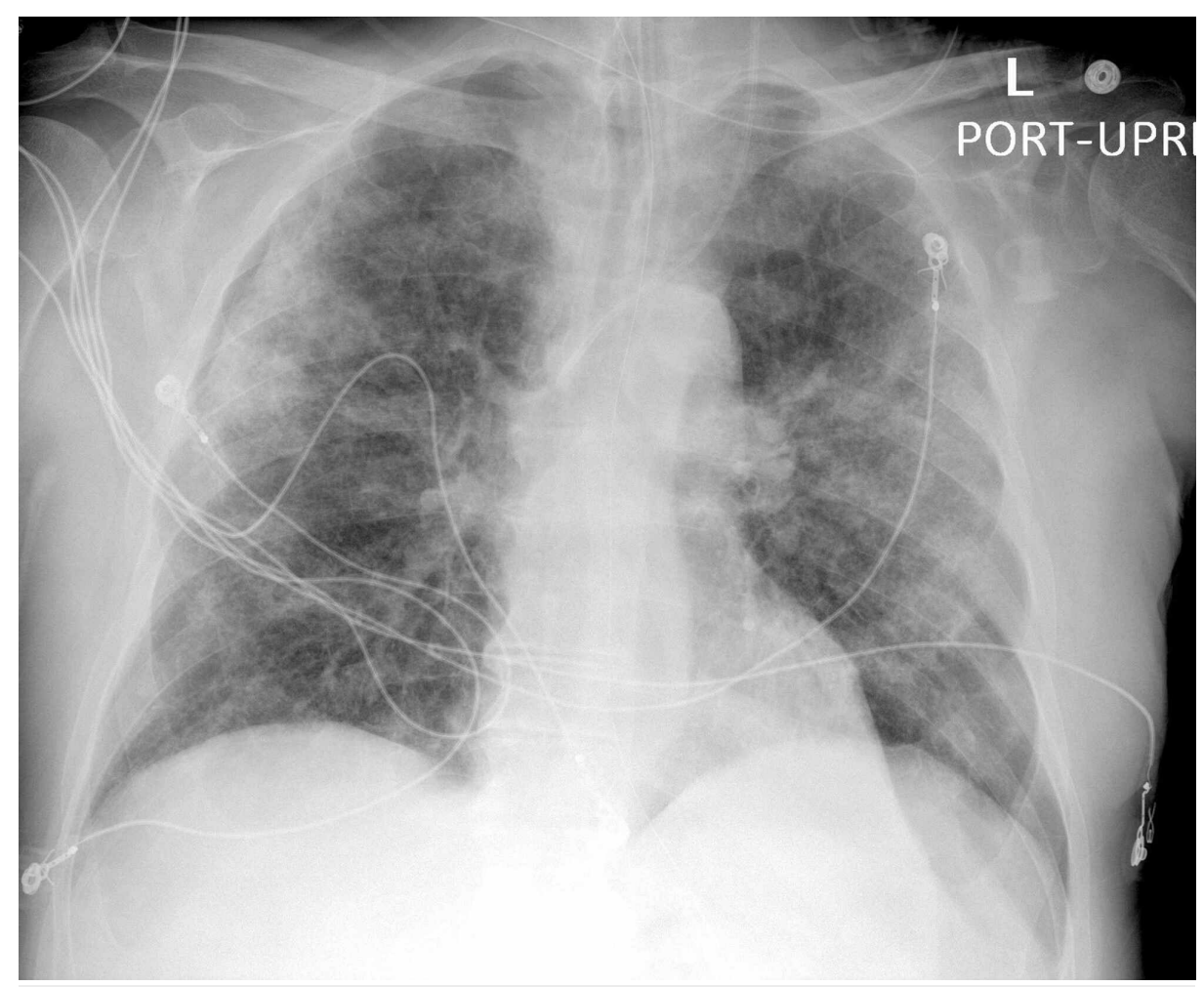

FIGURE 1: Chest x-ray of the patient indicating COVID-19 pneumonia

\section{Discussion}

Unlike bacterial infections, viral infections are less likely to cause remarkable changes in CSF glucose, cell count, or protein [8]. In this COVID-19 case, CSF findings such as increase in total protein, total cell count, and immunoglobulin G (IgG) indicated the presence of inflammation in the central nervous system. The marked increase (approximately four-fold) in NSE levels in CSF further supported the inflammatory invasion and neuronal injury. Additionally, this patient had persistent hypernatremia, which continued for over 10 
days, which may have contributed to the encephalopathy and osmotic demyelination.

\section{Conclusions}

NSE is an old marker, which is sensitive but poorly specific. Nevertheless, the findings are in tune with prior literature as NSE is a marker of neuronal damage. Based on this single observation, we suggest that NSE can be a candidate for a diagnostic/prognostic biomarker for neuroinflammation in COVID-19, especially for patients who have neurological symptoms. However, a study with a larger cohort is needed to evaluate the clinical significance.

\section{Additional Information \\ Disclosures}

Human subjects: Consent was obtained by all participants in this study. HCA IRB Manager issued approval 551. Ethics: This study was conducted in accordance with the Declaration of Helsinki and approved by the HCA institutional review board (IRB) Manager system (Protocol no: 2020-551). The requirement for written informed consent was waived as the obtained data was de-identified. Conflicts of interest: In compliance with the ICMJE uniform disclosure form, all authors declare the following: Payment/services info: All authors have declared that no financial support was received from any organization for the submitted work. Financial relationships: All authors have declared that they have no financial relationships at present or within the previous three years with any organizations that might have an interest in the submitted work. Other relationships: All authors have declared that there are no other relationships or activities that could appear to have influenced the submitted work.

\section{Acknowledgements}

This research was supported (in whole or in part) by Hospital Corporation of America (HCA) and/or an HCA affiliated entity. The views expressed in this publication represent those of the author(s) and do not necessarily represent the official views of HCA or any of its affiliated entities.

\section{References}

1. Isgrò MA, Bottoni P, Scatena R: Neuron-specific enolase as a biomarker: biochemical and clinical aspects . Adv Exp Med Biol. 2015, 867:125-143. 10.1007/978-94-017-7215-0_9

2. Haque A, Polcyn R, Matzelle D, Banik NL: New insights into the role of neuron-specific enolase in neuroinflammation, neurodegeneration, and neuroprotection. Brain Sci. 2018, 8:10.3390/brainsci8020033

3. Lamers KJ, Vos P, Verbeek MM, Rosmalen F, van Geel WJ, van Engelen BG: Protein S-100B, neuron-specific enolase (NSE), myelin basic protein (MBP) and glial fibrillary acidic protein (GFAP) in cerebrospinal fluid (CSF) and blood of neurological patients. Brain Res Bull. 2003, 61:261-264. 10.1016/s0361-9230(03)00089-3

4. Marchi N, Rasmussen P, Kapural M, et al.: Peripheral markers of brain damage and blood-brain barrier dysfunction. Restor Neurol Neurosci. 2003, 21:109-121.

5. Lima JE, Takayanagui OM, Garcia LV, Leite JP: Use of neuron-specific enolase for assessing the severity and outcome in patients with neurological disorders. Braz J Med Biol Res. 2004, 37:19-26. 10.1590/s0100879x2004000100003

6. Baig AM, Khaleeq A, Ali U, Syeda H: Evidence of the COVID-19 virus targeting the CNS: tissue distribution, host-virus interaction, and proposed neurotropic mechanisms. ACS Chem Neurosci. 2020, 11:995-998. 10.1021/acschemneuro.0c00122

7. Li YC, Bai WZ, Hashikawa T: The neuroinvasive potential of SARS-CoV2 may play a role in the respiratory failure of COVID-19 patients. J Med Virol. 2020, 92:552-555. 10.1002/jmv.25728

8. Hrishi AP, Sethuraman M: Cerebrospinal fluid (CSF) analysis and interpretation in neurocritical care for acute neurological conditions. Indian J Crit Care Med. 2019, 23:115-119. 10.5005/jp-journals-10071-23187 